Full length article

\title{
Aloe vera enhances the innate immune response of pacu (Piaractus mesopotamicus) after transport stress and combined heat killed Aeromonas hydrophila infection
}

\author{
Fábio S. Zanuzzo a, b, *, Rafael E. Sabioni ${ }^{\text {b }}$, Luz Natalia F. Montoya ${ }^{\text {b }}$, Gisele Favero ${ }^{\text {b }}$, \\ Elisabeth C. Urbinati a, b \\ a São Paulo State University (Unesp), Aquaculture Center of Unesp, Jaboticabal, Via de Acesso Prof. Paulo Donato Castelane, 14.884-900, Jaboticabal, São \\ Paulo, Brazil \\ b São Paulo State University (Unesp), School of Agricultural and Veterinarian Sciences, Jaboticabal, Via de Acesso Prof. Paulo Donato Castelane, 14.884-900, \\ Jaboticabal, São Paulo, Brazil
}

\section{A R T I C L E I N F O}

\section{Article history:}

Received 24 January 2017

Received in revised form

16 March 2017

Accepted 18 April 2017

Available online 19 April 2017

\section{Keywords:}

Innate immune response

Piaractus mesopotamicus

Immunostimulant

Stress

Medicinal herbs

\begin{abstract}
A B S T R A C T
In this study, pacu (Piaractus mesopotamicus) were fed with diets containing Aloe vera for 10 days prior to transport stress and infection with heat killed Aeromonas hydrophila. A. vera is popular around the world due to its medicinal properties, including immunostimulatory effects which was observed in this study. The results show that transport causes immunosuppression, an effect that was prevented by $A$. vera. Specifically, A. vera prevented reductions of both leukocyte respiratory burst and hemolytic activity of complement system caused by transport. Further, fish fed with $A$. vera also showed significantly higher leukocyte respiratory burst, serum lysozyme concentrations and activity of complement system $24 \mathrm{~h}$ after bacterial infection. Additionally, we observed that $A$. vera may modulate the innate response through activation of complement system during bacterial immune stimulation. In summary, A. vera extract enhanced innate immune parameters and consequently the ability of fish to cope with pathogens following transport stress. These findings show that $A$. vera has promise for use in aquaculture and add further evidence that medicinal herbs added to fish feed assist to prevent disease outbreaks.
\end{abstract}

() 2017 Elsevier Ltd. All rights reserved.

\section{Introduction}

The production of fish by aquaculture has increased significantly over the past few decades, jointly with the incidence of fish diseases. The increasing prevalence of diseases has been associated with intensive rearing procedures that cause stress such as netting, grading, transport, crowding and poor water quality, among others, which can affect the fish immune response and/or increase the virulence of pathogens [1]. Thus, studies focused on strengthening the immune system of fish are of great interest to researchers and producers.

Some methods to prevent disease outbreaks that have been used include chemotherapy, vaccination and immunostimulants products. However, the use of antibiotics and chemotherapy has

\footnotetext{
* Corresponding author. Department of Ocean Sciences and Biology, Memorial University of Newfoundland, St. John's A1C5S7, Canada.

E-mail address: fabioz@mun.ca (F.S. Zanuzzo).
}

created several problems, including the development of drug resistance $[2,3]$, toxic effects on fish and negative impacts on the environment and human health [4]. Vaccination has been considered a potential treatment. Nevertheless, a single vaccine, effective against only a single type of pathogen [5], also causes stressful handling [6] and can be expensive for widespread use by fish producers $[7,8]$. Further, the development of vaccines for heterogeneous species or multiple strains is extremely complex $[9,10]$. Thus, immunostimulants appear to be a viable alternative to these methods in the control of fish diseases, as recently suggested by Hang et al. [11]. Immunostimulants promote the activation of specific and/or non-specific defense mechanisms [12,13], and have been shown to be suitable for use in aquaculture [14]. Among the possible immunostimulants, medicinal plants arise showing great potential. Recent reviews [7,8,15-20] have emphasized the use of herbs as an emerging approach to enhance fish immunocompetence that may have substantial benefits for the aquaculture industry [21]. Finally, herbal extracts are easily obtained, and usually inexpensive, act against a broad spectrum of pathogens [22], and 
may have limited environmental impact due to their biodegradability [23].

Products derived from the Aloe vera are popular around the world due to their cosmetic and medicinal properties [24]. Several benefits to human and other animals health have been reported (e.g. chickens [25], mice [26], felines [27], dogs [28] and human beings [29]) including, wound healing, antibacterial, antiviral, antifungal, antidiabetic, anticancer, gastroprotective and immunemodulatory properties [25,30-33]. However, except for few studies [34-41] A. vera has been almost unexplored in aquaculture.

Given the potential benefits of $A$. vera extract in aquaculture, the main purpose of this study was to evaluate whether feeding fish with various levels of $A$. vera would affect their immune response to heat killed Aeromonas hydrophila injection after they have been subjects to transport stress. Further, we used the fish pacu (Piaractus mesopotamicus) as an experimental model because it is a commercially valuable South American species, especially in Brazil where its use in farming is constantly growing.

\section{Material and methods}

\subsection{Experimental animals}

We used a total of $240(71.3 \pm 3.3 \mathrm{~g})$ juvenile pacu, obtained from the Centro de Aquicultura of Univ. Estadual Paulista UNESP. The fish were held in 24 fiberglass tanks ( 100 l; 10 fish per tank) and initially fed with a commercial diet at a ration of $3 \%$ of their body mass twice a day. Tanks were supplied with water at a temperature of $\sim 29.5^{\circ} \mathrm{C}$, with oxygen and ammonia levels monitored daily $\left(\sim 6.5 \mathrm{mg} \mathrm{l}^{-1}\right.$ and $0.34-0.37 \mathrm{mg} \mathrm{l}^{-1}$, respectively). The photoperiod was $14 \mathrm{~h}$ light: $10 \mathrm{~h}$ dark.

\subsection{Experimental design: the effects of $A$. vera on stress and innate immune responses}

After 2 week of acclimation, the fish were fed one of four experimental diets ( 6 tanks per treatment) for 10 days: one control diet (no A. vera), and diets to which $5 \mathrm{~g} \mathrm{~kg}^{-1}(0.5 \%)$, $10 \mathrm{~g} \mathrm{~kg}^{-1}(1 \%)$ and $20 \mathrm{~g} \mathrm{~kg}^{-1}$ (2\%) of $A$. vera extract (see diet preparation below) were added. On the 11th day, the fish had their blood drawn by caudal puncture ( $\mathrm{n}=12$ per diet), and the remainders were transported in plastic bags for $4 \mathrm{~h}$ at a density of $166 \mathrm{~g} \mathrm{l}^{-1}$. Immediately at the return to the lab, 12 fish from each diet were sampled. The leftover fish were divided into 3 groups: uninjected (recovery), intra-peritoneally injected (IP) with PBS buffer (sham-injected) and IP with A. hydrophila. Fish were then sampled $24 \mathrm{~h}$ after injection $(\mathrm{n}=8)$. We measured plasma cortisol and glucose levels, leukocyte respiratory burst, serum lysozyme levels and hemolytic activity of the alternative complement system.

\subsection{Preparation of $A$. vera powder and experimental diets}

A total of 250 A. vera leaves (final weight of $75 \mathrm{~kg}$ ) were harvested, had their base cut off and placed in vertical position for $2 \mathrm{~h}$ to remove the aloin component by gravity; this component has emetic properties that could interfere with feed ingestion. Thereafter, the leaves were peeled, the whole parenchyma triturated in a food processor, and the $A$. vera gel centrifuged at $10,000 \times \mathrm{g}$ for $30 \mathrm{~min}$ at $4{ }^{\circ} \mathrm{C}$ to remove the fiber [42]. The supernatant was then separated and stored at $-20^{\circ} \mathrm{C}$. A . vera dehydration was performed using a spray drying process, during which a powder was formed from the liquid by rapidly drying it with hot air $\left( \pm 180^{\circ} \mathrm{C}\right)$. Initially, the dry matter content of $A$. vera gel was determined according to AOAC [43]. However, as the amount of dry matter in the $A$. vera gel was low $(0.76 \pm 0.005 \%)$ an excipient had to be added to improve the spray drying process. Then, the inclusion of different levels of Aerosil (Aerosil 200 Pharma, Evonic; Aerosil ${ }^{\circledR}$ colloidal silicon dioxide) were tested $(1,3,5,10$ and $30 \%$; data not shown), and based on these trials, $3 \%(\mathrm{w} / \mathrm{v})$ of Aerosil was added to the $A$. vera gel. During the spray drying process, the following parameters were used: inlet temperature $179.2 \pm 1.8^{\circ} \mathrm{C}$; outlet temperature $88.5^{\circ} \mathrm{C}$; atomizer was set to $30,000 \mathrm{rpm}$ with a depression of $15 \mathrm{~mm} \mathrm{CA}$; and an air flow rate of $81 \mathrm{~h}^{-1}$. After the dehydration process, we obtained a crude powder that contained $20.75 \%$ of $A$. vera. The powder was stored at $-20^{\circ} \mathrm{C}$ until use.

To prepare the experimental diets, a commercial diet (Fri-Aqua Onivoros: 4-6 mm; $12 \%$ moisture; $32 \%$ protein; $4.5 \%$ fat) was ground into powder. Thereafter, we weighed $24.09 \mathrm{~g}, 48.19 \mathrm{~g}$ and $96.38 \mathrm{~g}$ of the crude powder, corresponding respectively to $5 \mathrm{~g}, 10 \mathrm{~g}$ and $20 \mathrm{~g}$ of $A$. vera, using the rate of $20.75 \%$ obtained above. Then, the various amount of $A$. vera were suspended in 0.51 of water and sprayed onto the powdered feed. These diets, corresponding to 0.5 , $1 \%$ and $2 \%$ A. vera $(\mathrm{w} / \mathrm{w})$, were then dried and pelleted. To avoid interference on the palatability, the control diet contained a similar amount of Aerosil.

\subsection{Preparation of A. hydrophila and experimental infection}

The A. hydrophila (strain A135, LAPOA, Jaboticabal, São Paulo, Brazil) was identified by sequencing of the 16S rDNA (the strain used showed a similarity of $97 \%$ with GenBank accession \# ATCC 7966). Bacteria were stored in TSB (Tryptic Soy Broth, Hi Media) medium with $30 \%$ glycerol (sterile) at $-80^{\circ} \mathrm{C}$. For use in trials, an aliquot of $20 \mu \mathrm{l}$ was added into $5 \mathrm{ml}$ of autoclaved TSB medium and incubated in a bacteriological incubator at $28{ }^{\circ} \mathrm{C}$, for $24 \mathrm{~h}$. Thereafter, $700 \mathrm{ml}$ of autoclaved TSB medium was added and incubated again using the same conditions. This bacterial suspension was centrifuged at $12,000 \times \mathrm{g}$ for $20 \mathrm{~min}$ and the supernatant was discarded. Subsequently, the remaining pellet was washed twice with PBS buffer $(0.01 \mathrm{M})$ and centrifugation steps of $12,000 \times \mathrm{g}$ for 20 min. Finally, the pellet was re-suspended in PBS $(0.01 \mathrm{M})$ and adjusted according to the McFarland turbidity standard to obtain a suspension of $3 \times 10^{9} \mathrm{cfu} \mathrm{ml}^{-1}$, that was inactivated ${ }^{1}$ in a water bath at $40{ }^{\circ} \mathrm{C}$ for $30 \mathrm{~min}$ [44], prior.

The fish designated to receive IP injections (PBS or $A$. hydrophila) were netted from the holding tanks and anaesthetized in water containing $0.1 \mathrm{~g} \mathrm{l}^{-1}$ MS-222 (tricaine methanesulfonate; Sigma-Aldrich, São Paulo, Brazil; \#E10521) until ventilatory movements ceased. Their mass was recorded and they were given a $4 \mu \mathrm{lg}^{-1} \mathrm{IP}$ injection of $A$. hydrophila or PBS.

\subsection{Fish sampling}

Fish were anaesthetized and blood samples were drawn from the caudal vessel using syringes without anticoagulant, and dispensed into heparinized microtubes (plasma), microtubes containing the anticoagulant Glistab $^{\circledR}$ (plasma for glucose) and microtubes without anticoagulant (serum). Whole blood was used immediately to measure leukocyte respiratory burst. To obtain plasma, blood samples were centrifuged for $10 \mathrm{~min}$ at $3000 \times \mathrm{g}$. Glucose levels were determined immediately, whereas the plasma for the analysis of cortisol levels was stored at $-80{ }^{\circ} \mathrm{C}$. To obtain serum for the analysis of hemolytic activity of complement system and serum lysozyme concentration, the blood was allowed to clot

\footnotetext{
${ }^{1}$ Inactivation of bacteria was chosen to stimulate the pacu's immune system but avoid any significant mortality, since that transport could increase the susceptibility to the bacterial challenge.
} 
at room temperature for $3 \mathrm{~h}$, and then centrifuged at $3000 \times \mathrm{g}$ for $10 \mathrm{~min}$. Serum was stored at $-80^{\circ} \mathrm{C}$ prior to the analyses.

\subsection{Glucose and cortisol plasma assays}

Plasma glucose concentrations were determined by enzymatic method (Labtest kit, REF: 1012, São Paulo, Brazil, http://labtest.com. br/en/reagents/glucose-liquiform-vet) using spectrophotometer (Model Genesys 10S, Thermo Scientific Inc., Madison, WI, USA), and cortisol levels were measured using a commercial ELISA kit (DRG International, Inc., USA; Cortisol Enzyme-Linked ImmunoSorbent Assay, EIA 1887) following the manufacturer's instructions.

\subsection{Immunological assays}

\subsubsection{Leukocyte respiratory burst}

The production of reactive oxygen species was measured using NBT (nitrotetrazolium blue chloride, Sigma-Aldrich, São Paulo, Brazil; \#N6876), following the protocol of Sahoo et al. [45]. Immediately after bleeding, $100 \mu$ l of heparinized blood were incubated with an equal volume of NBT buffer $(0.2 \%)$ at room temperature for $30 \mathrm{~min}$. Thereafter, $1 \mathrm{ml}$ of dimethylformamide (DMF, Sigma-Aldrich, São Paulo, Brazil; \#227056) was added to the samples, that were read in a spectrophotometer (Model Genesys 10S, Thermo Scientific Inc., Madison, WI, USA) at wavelength $540 \mathrm{~nm}$, at room temperature.

\subsubsection{Serum lysozyme concentration}

Serum lysozyme concentration was determined according to Demers and Bayne [46] with modifications by Zanuzzo et al. [36]. Briefly, standard solutions of hen egg white lysozyme (SigmaAldrich, São Paulo, SP, Brazil; \#L6876) and serum samples were placed into a 96-well plate in triplicate with a suspension of Micrococcus lysodeikticus (Sigma-Aldrich, São Paulo, Brazil; \#M3770). After mixing, absorbance was measured at $450 \mathrm{~nm}$ over 10 min using a microplate reader (Model Multiskan Ascent, Thermo Fisher Scientific Inc., Madison, WI, USA) at room temperature. The rate of decrease in absorbance for each sample was then compared to that obtained with the standard curve.

\subsubsection{Hemolytic activity of alternative complement pathway}

Serum hemolytic activity of the complement (alternative pathway) was measured according to Zanuzzo et al. [36] with modifications for use with pacu blood as follows. Initially, a sample of rabbit blood was collected and the rabbit erythrocytes (RaRBCs) were washed and isolated according to Zanuzzo et al. [36]. To optimize the assay for pacu, a series of dilutions (1:24, 1:12, 1:8, 1:6 and $1: 4$ in a final volume of $200 \mu \mathrm{l}$ ) was made by mixing a pool of aliquots of all serum samples with TEA-EGTA- $\mathrm{Mg}^{2+}$ buffer (triethanolamine ethylene glycol tetraacetic acid; $8 \mathrm{mM}$, with $2 \mathrm{mM}$ of $\mathrm{Mg}^{2+}$ and $0.1 \%$ gelatin, $\mathrm{pH} 7.4$ ) and the RaRBC suspension, and measuring absorbance at $700 \mathrm{~nm}$ using a spectrophotometer (Model Genesys 10S, Thermo Scientific Inc., Madison, WI, USA) at $15,20,25,30,35$ and $40{ }^{\circ} \mathrm{C}$ (data not shown). Based on this preliminary work, the assay was carried out with a 1:8 dilution at $25{ }^{\circ} \mathrm{C}$. Hemolytic complement activity $\left(\mathrm{ACH}_{50}\right)$ for each sample was measured as the time (seconds) required for the initial optical density to be reduced by one-half ( $50 \%$ of RaRBC hemolysis by the alternative pathway). To obtain the activity of complement system per second (reduction of DO $\mathrm{sec}^{-1}$ ), we used:

$\mathrm{ACH}=\frac{1}{\text { Time to obtain the rate at which } 50 \% \text { lysis is reached }}$

\subsection{Statistical analyses}

This experiment was analyzed as a 4 (diets) x 5 (sampling point) two-way ANOVA, followed by a Duncan's Multiple Range Test. Data were transformed prior to statistical analysis as they failed normality (Cramer Von Mises) and/or homoscedasticity tests (Brown-Forsythe). All analyses were performed using the Statistical Analysis Software (SAS, version 9.2) package with $\mathrm{P}<0.05$ set as the level of statistical significance. Values in the text and figures are means \pm 1 standard error (S.E.) of the mean.

\subsection{Animal welfare statement}

The experimental procedures described were approved by the Comissão de Ética no Uso de Animais (CEUA - Protocol 002111/12) and performed in accordance with the guidelines for the ethical principles in animal experimentation adopted by the Colégio Brasileiro de Experimentação (COBEA, Brasília, Brazil).

\section{Results}

No mortality was observed during the experimental period. Plasma glucose and cortisol concentrations were approx. 2.5-3fold higher in all treatments immediately after transport (arrival) compared to the initial sampling $(\mathrm{P}<0.05)$, without differences among treatments (Fig. 1). Glucose levels were significantly lower (i.e. by $40-60 \%$ ) in all fish groups $24 \mathrm{~h}$ after transport (recovery) compared to arrival values (Fig. 1A). There were slight differences in plasma glucose levels among groups $24 \mathrm{~h}$ after transport, which were probably not biologically significant. Neither A. hydroplila nor PBS injection had any effect in fish fed with the control diet $(\mathrm{P}<0.05$, Fig. 1A).

Plasma cortisol levels differed among diet treatments $24 \mathrm{~h}$ after transport (recovery), when fish fed with 1 and $2 \% A$. vera diets had levels higher than those of control fish $(\mathrm{P}<0.05$, Fig. 1B). Cortisol levels in control fish returned close to the initial values $24 \mathrm{~h}$ after transport (recovery; Fig. 1B) in contrast with fish fed with $A$. vera, which remained close to arrival values $(\mathrm{P}<0.05$, Fig. $1 \mathrm{~B})$. There was no effect of $A$. hydroplila vs. PBS injection on cortisol levels in fish fed with the control diet. In contrast, $A$. vera treatment generally decreased the levels of cortisol in A. hydrophila injected fish but the combination of $1 \% A$. vera and IP with $A$. hydrophila resulted in statistically significant lower cortisol values compared to control fish $(\mathrm{P}<0.05$, Fig. 1B).

Leukocyte respiratory burst (LRB) was significantly lower in control fish immediately after transport (arrival) compared to initial control values and those observed $24 \mathrm{~h}$ after transport (recovery). In addition, fish fed with the $A$. vera diets had significantly higher (approx. 15\%) LRB compared to fish fed with control diet immediately after transport (arrival; Fig. 2A). No significant difference was observed among diet treatments $24 \mathrm{~h}$ after transport (recovery) or when fish were injected with PBS (Fig. 2A). Further, the LRB was lower in control fish when injected with $A$. hydrophila compared to PBS injection ( 20\%). Finally, all fish fed with $A$. vera diets had higher LRB values than control fish when injected with A. hydrophila (Fig. 2A).

Serum lysozyme concentrations (SLC) decreased immediately after transport (arrival) in fish fed with 0.5 and $2 \%$ of $A$. vera diets. Those fed with 0.5 and $2 \%$ A. vera diets had higher SLC 24 h after transport (recovery) compared to control fish and those fed with $1 \%$ A. vera $(\mathrm{P}<0.05$, Fig. $2 \mathrm{~B})$. IP injection with $A$. hydrophila led to significant increases in SLC compared to PBS values in all treatments. This response in the $A$. hydrophia group was also affected by 
A

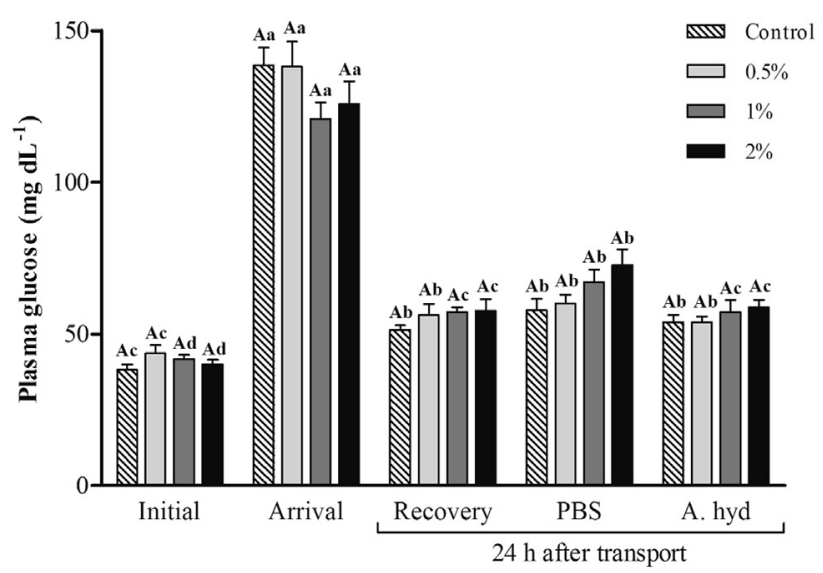

B

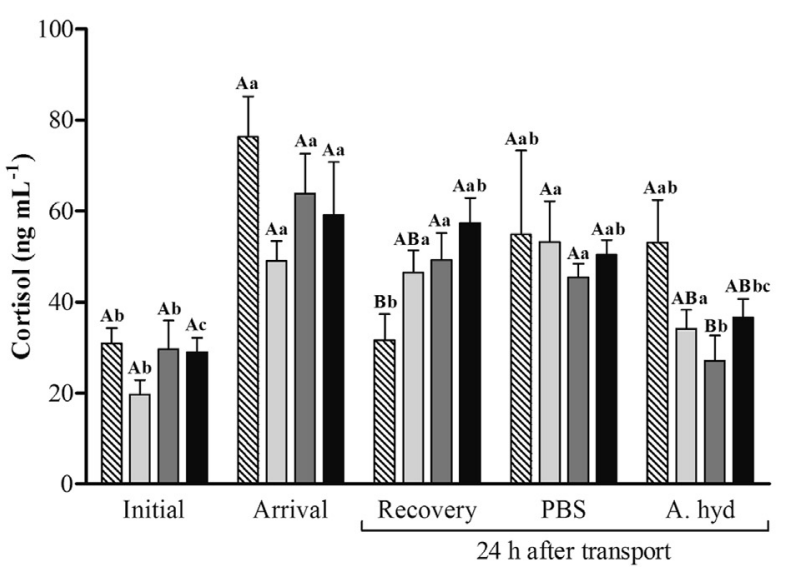

Fig. 1. Plasma glucose (A) and cortisol (B) concentrations in pacu fed with $A$. vera diets $(0 \%$; $0.5 \%$; $1 \%$; and $2 \%$ ) before transport (Initial, $n=12$ ), immediately after transport (Arrival, $\mathrm{n}=12$ ), $24 \mathrm{~h}$ after transport (Recovery, $\mathrm{n}=8$ ) and after they were given an IP injection with PBS or $A$. hydrophila $(\mathrm{n}=8)$. Different capital letters indicate differences among diets at a given time point. Different lower case letters indicate a difference between sampling points within a group $(\mathrm{P}<0.05)$. Values are means \pm 1 standard error (S.E.).

diet. The SLC was higher (by $4.5 \mathrm{ng} \mu \mathrm{l}^{-1}$ ) in fish fed with $1 \%$ and $2 \%$ A. vera diets compared to control fish or those fed with $0.5 \%$ A. vera ( $\mathrm{P}<0.05$, Fig. 2B).

Hemolytic activity of complement system $(\mathrm{ACH})$ was lower in pacu fed with $2 \% A$. vera diet compared to all other groups at the initial sampling time $(\mathrm{P}<0.05$, Fig. $2 \mathrm{C})$. Immediately after transport (arrival), control fish showed a significantly reduction in $\mathrm{ACH}$ compared to initial values (2-fold). However this reduction was prevented in fish fed with $A$. vera diets as the $\mathrm{ACH}$ in these groups was approx. 2-fold higher than control $(P<0.05$, Fig. $2-C)$. The $\mathrm{ACH} 24 \mathrm{~h}$ after transport (recovery) was approx. 2.5-fold higher in fish fed with 1 and $2 \% A$. vera diets than in control (Fig. $2-C$ ). The dietary $A$. vera provoked significant improvement in the concentration-dependent effects on the ACH in PBS and A. hydrophila injected fish compared to control values $(\mathrm{P}<0.05$, Fig. $2-\mathrm{C}$ ).

\section{Discussion}

Recently increasing attention has been given to the use of plants products for disease control in aquaculture, in view of the number of reviews published [7-9,15-22,47-49]. However, A. vera has received only a rare mention (e.g. Hai [16] and Vallejos-Vidal et al.
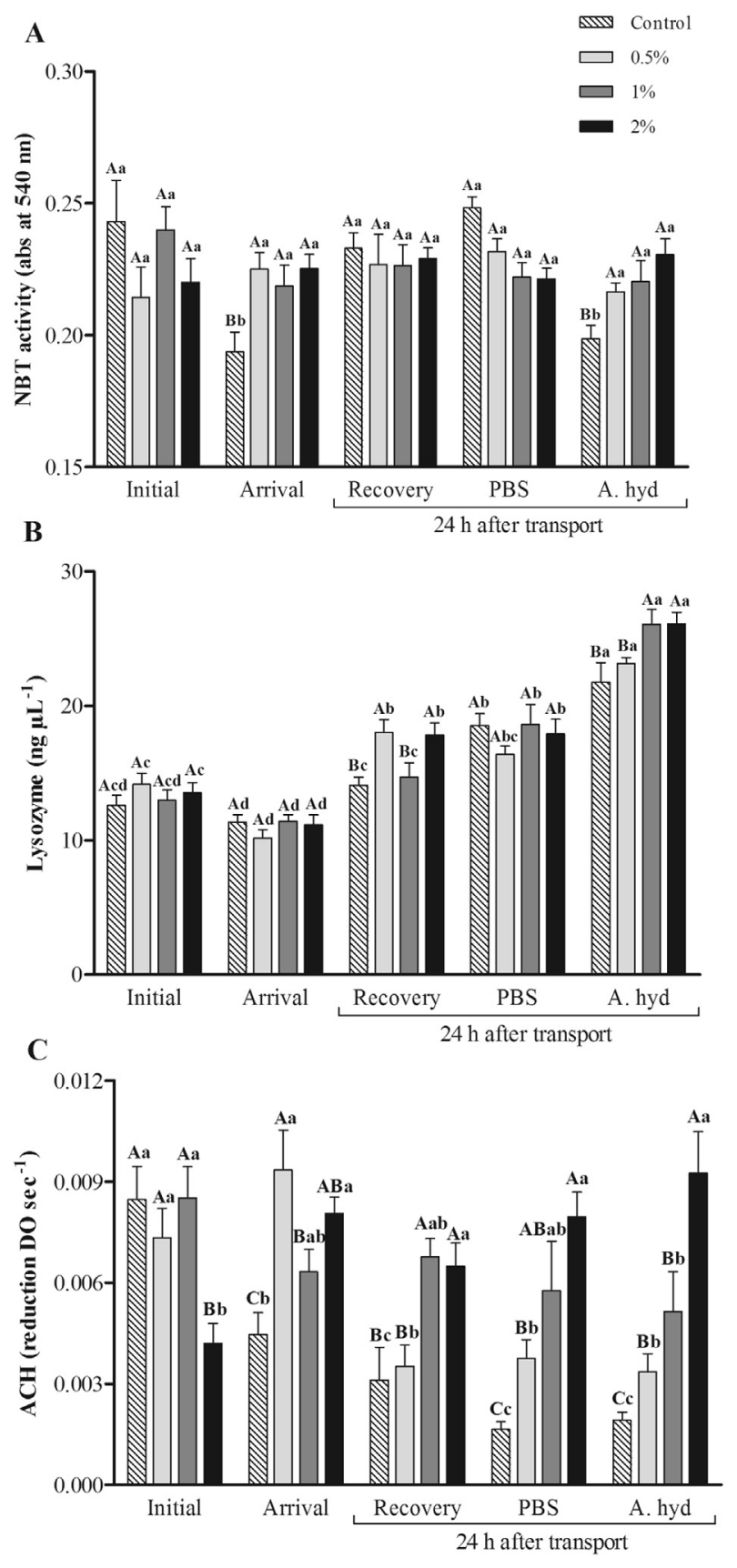

Fig. 2. Leukocyte respiratory burst (NBT activity - A), serum lysozyme concentrations (B) and serum complement activity $(\mathrm{ACH}-\mathrm{C})$ in pacu fed with $A$. vera diets $(0 \% ; 0.5 \%$; $1 \%$; and $2 \%$ ) before transport (Initial, $\mathrm{n}=12$ ), immediately after transport (Arrival, $\mathrm{n}=12$ ), $24 \mathrm{~h}$ after transport (Recovery, $\mathrm{n}=8$ ) and after they were given an IP injection with PBS or A. hydrophila $(\mathrm{n}=8)$. Different capital letters indicate differences among diets at a given time point. Different lower case letters indicate a difference between sampling points within a group $(\mathrm{P}<0.05)$. Values are means \pm 1 standard error $($ S.E. $)$.

[19]), despite the fact that it contains several compounds that may provide this herb with a great potential to improve fish production. Here, we found that dietary $A$. vera supplementation prevented the immunosuppression provoked by the stress of transport, injection and bacterial infection; treatment also enhanced SLC tested after heat killed A. hydrophila infection. Furthermore, there was a dosedependent prevention of the loss of $\mathrm{ACH}$ after treatment with $A$. vera diets, which also appears to have modulated the other innate immune parameters when fish were exposed a bacterial 
immune stimulation. Finally, our findings confirm that $A$. vera increased the resistance against a pathogen infection and has promise for use in aquaculture, especially for being applied before stressful handling to increase fish protection and prevent disease outbreaks.

Blood parameters such as plasma glucose and cortisol levels are often used as indicators of stress [50]. In our study, plasma glucose and cortisol levels increased immediately after transport confirming the stress caused by the procedure. The results also show that transport impaired LRB and ACH. These deleterious effects on immune responses associated to stressful aquaculture operations are widely known [1,51,52]. Moreover, we found that $A$. vera slowed the recovery of cortisol level from high relative to control fish $24 \mathrm{~h}$ after transport (recovery) but reduced cortisol levels relative to control fish $24 \mathrm{~h}$ after injection with $A$. hydrophila. At present, we do not have an explanation for this result. Zanuzzo et al. [53] showed that steelhead trout (Oncorhynchus mykiss) fed with $0.5 \% A$. vera during 8 weeks had resting cortisol levels one-half of those of the control fish. Tilapia (Oreochromis niloticus) fed with A. vera diets during 60 days also had significantly difference in cortisol level compare to control fish [39]. These data add evidence that this compound may modulate cortisol levels in fish. Nonetheless, additional experiments may confirm/determine the extent of the effects of $A$. vera on the cortisol levels in fish.

Leukocyte respiratory burst plays an essential role in the control of host immune response and resistance to pathogens [54]. Selvaraj et al. [55] observed a dramatically reduced survival in vitro of A. hydrophila exposed to macrophages obtained from fish with enhanced oxygen burst activity. In this study, LRB decreased immediately after transport in control fish, which would likely result in enhanced susceptibility to disease. However, a reduction of LRB in fish fed with $A$. vera was not observe, suggesting a protective effect triggered by the herb. We also notice that $A$. vera prevented LRB reduction after bacterial immune stimulation. Thus, these results suggest that $A$. vera improved the resistance of pacu against a bacterial infection. In previous study, Zanuzzo, et al. [35] and Zanuzzo et al. [38] also showed that adding $A$. vera to the water prevented the reduction of LRB promoted by the stress (transport and induced spawning, respectively) in matrinxã (Brycon amazonicus). Additionally, two dihydrocoumarins isolated from $A$. vera stimulated the in vitro phagocytic capacity and the oxygen respiratory burst of macrophages in rat [56]. Some reports also have shown that oral administration of other herbal supplements enhanced the LRB in different fish species, such as tilapia (O. mossambicus) fed with diets containing Eclipta alba [57], Astragalus membranaceus and Lonicera japonica [58], and rainbow trout (0. mykiss) fed with diets containing Zingiber officinale [47].

Lysozyme is an important bactericidal molecule of the innate immune system [59]. In this study, SLC increased in all fish groups following bacterial immune stimulation. Enhanced serum lysozyme activity was also observed in carp (Cyprinus carp) infected with $A$. punctate [60] and in Atlantic salmon (Salmo salar) experimentally challenged with $A$. salmonicida [61]. In addition, our results show that fish fed with 1 and $2 \% A$. vera diets significantly enhanced SLC after a bacterial immune stimulation. Even with different active compounds, other medicinal herbs have also shown positive effects on SLC in fish. Ardo et al. [58] showed that $A$. membranaceus and $L$. japonica significantly enhanced plasma lysozyme activity in tilapia (Oreochromis niloticus). Verma et al. [62], using the indigenous plant Leucaena leucocephala and Ficus benghalensis, also showed increased lysozyme activity in Clarias gariepinus after infection with $A$. hydrophila. Tilapia (O. mossambicus) fed with diets containing E. alba extract had significant increase in serum lysozyme activity [57].

The complement system is an important component of the innate immunity that plays an essential role in detecting the presence of pathogens (for a review see Boshra et al. [63] and Zhang and Cui [64]). The complement system has been also designated as an indicator of fish immune competence because it is downregulated in many situations of stress [65] and can be activated by immunostimulants [57,66-68]. Several orally administrated herbs have been shown enhance $\mathrm{ACH}$ in fish, such as mistletoe extract, Viscum album coloratum [69], Rauvolfia tetraphylla [70], E. alba [57], Tinospora cordifolia [71], Nyctanthes arbortristis [72], triherbal leaf extract from Azadirachta indica, Ocimum sanctum and Curcuma longa [73] and Punica granatum [74]. In this study, the dietary $A$. vera stimulated the $\mathrm{ACH}$ that was depressed after transport. Moreover, $24 \mathrm{~h}$ after transport $A$. vera also prevented a reduction caused by transport, in a dose-dependent pattern, in fish injected with PBS and heat killed $A$. hydrophila. These results confirm the immunostimulatory property of $A$. vera, in response to injury and its enhancement of resistance against bacterial infection in pacu.

The most interesting findings of this study involved the complement system. Herein, $24 \mathrm{~h}$ after transport fish fed with $A$. vera and injected with PBS had higher complement system activity compared to control, in a dose-dependent pattern; however no differences were observed in LRB and SLC. Although, when fish were fed with $A$. vera and exposed to a bacterial immune stimulation, an increase in a dose-dependent pattern were also observed in LRB and SLC. Complement mediates opsonization of the pathogen, allowing the recognition of these microbes by phagocytes and consequently phagocytosis [63]. The activation of phagocytosis induces other antimicrobial mechanisms, such as release of lysosomal enzymes and production of reactive oxygen species [75]. When the outer cell wall of bacteria is disrupted by the complement, exposing the inner peptidoglycan layer of bacteria, then lysozyme becomes effective [59]. Fragments of C3 also have been shown to induce inflammation and stimulating the respiratory burst in leukocytes isolated from rainbow trout [76]. Based on the above statements, these data support an important finding. A. vera prevented a reduction of alternative complement system activity, which in combination with bacterial immune stimulation could have modulated LRB and SLC in a dose-dependent pattern. This finding indicates evidence of the mechanism of action of $A$. vera as discussed below. However, even of it is well-known that complement system could mediate innate immunity in fish, due to in vitro functional experiments or by homology with the complement system of mammals [77], this is the first evidence in vivo of modulation of innate immunity by complement system from a functional point of view in fish. There is limited amount of functional data on the physiological role of the fish complement system $[63,64]$, even the identification of complement system components has been a relatively recent discovery in fish [77].

The responses elicited by $A$. vera are complex, in part due to the composition of the extract, which has more than 75 biologically active compounds with multiple biological activities [31]. However, the immune-modulatory property of $A$. vera has been mainly attributed to their polysaccharide (e.g. aloeride [78]) and glycoprotein fractions, such as mannose (e.g. acemannan [79]). Although, the exact immune-modulatory mechanisms of herbal extracts in fish are still unknown [8,9], it could be speculated that A. vera could act through toll-like receptors (TLR) [19,80], a group of structurally related molecules that are expressed on the cell surface and serve as pattern recognition receptors (PRR) to detect the presence of microbial infection [81]. These TLR have been found to recognize immunomodulating substances such as zymosan, BCG cell walls, heat shock protein 60 , polymannuronic acid polymers and LPS [82]. Some reports have shown in mammals that polysaccharides isolated from medicinal herbs, such as Acanthopanax 
senticosus, roots of A. embranaceus and Platycodon grandiflorum, activated macrophages and $B$ cells proliferation, cytokine release and production of nitric oxide via the activation of TLR-4 [83-85]. The $A$. vera could act via TLR- 4 since these receptors bind to mannose molecules, one compound of the A. vera extract. Nevertheless, there is a body of evidence indicating extensive cross-talk between TLR and complement signaling pathway [86,87]. These two components are critical for first-line host defense and revealed a marked synergistic interaction between TLR and complement [88]. Kaczorowski et al. [89] demonstrated in a murine macrophage cell line that TLR stimulation leads to synthesis and release of complement components by macrophages, and this effect was TLR4-dependent. However, as mentioned above, $A$. vera modulated the alternative complement system in a dose-dependent pattern, which reinforces the hypothesis that $A$. vera could act through cross-talk between TLR-4 pathway and complement. Thus, when fish fed with $A$. vera were exposed to a bacterial immune stimulation, the higher activity of complement system may cause a higher release of anaphylatoxin molecules, increasing the inflammatory process and up-regulating LRB and SLC. Moreover, the presence of a pathogen could activate other pathways and the recognition of A. vera could be also performed by multiple pattern recognition receptors, which could include TLR but also non-TLRs. These results suggest a plausible mechanism of how $A$. vera may promote immune-modulation and assist in understanding the mechanism of action of immunostimulants in fish. Recent studies also reinforce the hypothesis that this mechanism of the immunostimulants is mediated by TLR signaling pathways in fish [90-92].

In conclusion, dietary $A$. vera either improved or prevented loss of innate immune activity in pacu after a stressful handling and a bacterial infection. Recently, increasing efforts have been made to improve fish immunocompetence, and these results are promising, since 1) a possible commercial large-scale process to prepare the herb extract was demonstrated as viable 2 ) a relevant enhancement or prevention of loss of the innate immune response induced by A. vera was observed, 3 ) oral administration of the extract was employed, which has been shown to be most suitable for aquaculture $[8,9]$ and 4 ) the medicinal herb used here is easily obtained and inexpensive, can act against a wide range of pathogens and have limited environmental impact. Furthermore, studies on the isolation/identification of $A$. vera bioactive compounds that are responsible for such activities and the exact mechanism by which $A$. vera affects fish immunity are necessary. Finally, the extent of the effects of $A$. vera taking into account dose and duration of exposure should be investigated, since both are potential factors for overdosing [9] which was recent observed by Gabriel et al. [39].

\section{Acknowledgments}

We thank the company João Castilho Reche - Sítio Fundinho Mogi Mirim|SP for the donation of the A. vera leaves. We are very grateful to Dr. Rodney A. F. Rodrigues (UNICAMP), Dr. Marcelo N. da Costa, Dr. Edison P. de Ros Triboli and the technician Douglas D. Justina who helped with $A$. vera preparation and dehydration. This research was funded by the CAPES (Coordenação de Aperfeiçoamento de Pessoal de Nível Superior) "Bolsista da Capes Proc. no. 1879-13-8" awarded to FSZ.

\section{References}

[1] L. Tort, Stress and immune modulation in fish, Dev. Comp. Immunol. 35 (12) (2011) 1366-1375.

[2] C.D. Miranda, R. Zemelman, Antimicrobial multiresistance in bacteria isolated from freshwater Chilean salmon farms, Sci. Total Environ. 293 (1-3) (2002) 207-218

[3] E.E. Seyfried, R.J. Newton, K.F. Rubert, J.A. Pedersen, K.D. McMahon,
Occurrence of tetracycline resistance genes in aquaculture facilities with varying use of oxytetracycline, Microbial. Ecol. 59 (4) (2010) 799-807.

[4] F.C. Cabello, Heavy use of prophylactic antibiotics in aquaculture: a growing problem for human and animal health and for the environment, Environ. Microbiol. 8 (7) (2006) 1137-1144.

[5] M.R. Chandran, B.V. Aruna, S.M. Logambal, R.D. Michael, Immunisation of Indian major carps against Aeromonas hydrophila by intraperitoneal injection, Fish. Shellfish Immunol. 13 (1) (2002) 1-9.

[6] A.L. Murray, R.J. Pascho, S.W. Alcorn, W.T. Fairgrieve, K.D. Shearer, D. Roley, Effects of various feed supplements containing fish protein hydrolysate or fish processing by-products on the innate immune functions of juvenile coho salmon (Oncorhynchus kisutch), Aquaculture 220 (1-4) (2003) 643-653.

[7] B. Vaseeharan, R. Thaya, Medicinal plant derivatives as immunostimulants: an alternative to chemotherapeutics and antibiotics in aquaculture, Aquacult. Int. 22 (3) (2014) 1079-1091.

[8] M. Reverter, N. Bontemps, D. Lecchini, B. Banaigs, P. Sasal, Use of plant extracts in fish aquaculture as an alternative to chemotherapy: current status and future perspectives, Aquaculture 433 (0) (2014) 50-61.

[9] R. Harikrishnan, C. Balasundaram, M.S. Heo, Impact of plant products on innate and adaptive immune system of cultured finfish and shellfish, Aquaculture $317(1-4)(2011) 1-15$.

[10] B. Dixon, Vaccines for finfish aquaculture: what do we need to know to make them work? Electron. J. Biotechn 15 (5) (2012).

[11] B.T.B. Hang, N.T. Phuong, P. Kestemont, Can immunostimulants efficiently replace antibiotic in striped catfish (Pangasianodon hypophthalmus) against bacterial infection by Edwardsiella ictaluri? Fish. Shellfish Immunol. 40 (2) (2014) 556-562.

[12] D.P. Anderson, G. Jeney, Immunostimulants added to injected Aeromonas salmonicida bacterin enhance the defense mechanisms and protection in rainbow trout (Oncorhynchus Mykiss), Vet. Immunol. Immunop 34 (3-4) (1992) 379-389.

[13] P.K. Sahoo, Role of immunostimulants in disease resistance of fish, CAB Reviews: perspectives in Agriculture, Vet. Sci. Nutr. Nat. Resour. 2 (2007).

[14] I. Bricknell, R.A. Dalmo, The use of immunostimulants in fish larval aquaculture, Fish. Shellfish Immunol. 19 (5) (2005) 457-472.

[15] A. Newaj-Fyzul, B. Austin, Probiotics, immunostimulants, plant products and oral vaccines, and their role as feed supplements in the control of bacterial fish diseases, J. Fish. Dis. 38 (11) (2014) 937-955.

[16] N.V. Hai, The use of medicinal plants as immunostimulants in aquaculture: a review, Aquaculture 446 (2015) 88-96.

[17] E. Ringo, S.K. Song, Application of dietary supplements (synbiotics and probiotics in combination with plant products and $\beta$-glucans) in aquaculture, Aquacult. Nut 22 (1) (2016) 4-24.

[18] D. Carbone, C. Faggio, Importance of prebiotics in aquaculture as immunostimulants. Effects on immune system of Sparus aurata and Dicentrarchus labrax, Fish. Shellfish Immunol. 54 (2016) 172-178.

[19] E. Vallejos-Vidal, F. Reyes-Lopez, M. Teles, S. MacKenzie, The response of fish to immunostimulant diets, Fish. Shellfish Immunol. 56 (2016) 34-69.

[20] W. Wang, J. Sun, C.J. Liu, Z. Xue, Application of immunostimulants in aquaculture: current knowledge and future perspectives, Aquacult. Res. 48 (1) (2017) $1-23$

[21] T. Citarasu, Herbal biomedicines: a new opportunity for aquaculture industry, Aquacult. Int. 18 (3) (2010) 403-414.

[22] J. Galina, G. Yin, L. Ardo, Z. Jeney, The use of immunostimulating herbs in fish. An overview of research, Fish. Physiol. Biochem. 35 (4) (2009) 669-676.

[23] G.J. Yin, L. Ardo, K.D. Thompson, A. Adams, Z. Jeney, G. Jeney, Chinese herbs (Astragalus radix and Ganoderma lucidum) enhance immune response of carp, Cyprinus carpio, and protection against Aeromonas hydrophila, Fish. Shellfish Immunol. 26 (1) (2009) 140-145.

[24] S. Javed, R. Atta ur, Aloe vera gel in food, health products, and cosmetics industry, in: R. Atta ur (Ed.), Studies in Natural Products Chemistry, Elsevier, Karachi, 2014, pp. 261-285.

[25] M. Akhtar, A. Hai, M.M. Awais, Z. Iqbal, F. Muhammad, A. ul Haq, M.I. Anwar, Immunostimulatory and protective effects of Aloe vera against coccidiosis in industrial broiler chickens, Vet. Parasitol. 186 (3-4) (2012) 170-177.

[26] N. Akev, G. Turkay, A. Can, A. Gurel, F. Yildiz, H. Yardibi, E.E. Ekiz, H. Uzun, Effect of Aloe vera leaf pulp extract on Ehrlich ascites tumours in mice, Eur. J. Cancer. Prev. 16 (2) (2007) 151-157.

[27] C. Harris, K. Pierce, G. King, K.M. Yates, J. Hall, I. Tizard, Efficacy of acemannan in treatment of canine and feline spontaneous neoplasms, Mol. Biother 3 (4) (1991) 207-213.

[28] N. Altug, N. Yuksek, Z.T. Agaoglu, Immunostimulatory effects of aloe vera and $\beta$-glucan on cellular and humoral immune responses following vaccination with polyvalent vaccines in dogs, Kafkas Univ. Vet. Fak. 16 (3) (2010) 405-412.

[29] K.M. Abdullah, A. Abdullah, M.L. Johnson, J.J. Bilski, K. Petry, D.A. Redmer, L.P. Reynolds, A.T. Grazul-Bilska, Effects of Aloe vera on gap junctional intercellular communication and proliferation of human diabetic and nondiabetic skin fibroblasts, J. Altern. Complem. Med. 9 (5) (2003) 711-718.

[30] E.V. Christaki, P.C. Florou-Paneri, Aloe vera: a plant for many uses, J. Food Agric. Environ. 8 (2) (2010) 245-249.

[31] T. Reynolds, A.C. Dweck, Aloe vera leaf gel: a review update, J. Ethnopharmacol. 68 (1-3) (1999) 3-37.

[32] J.H. Hamman, Composition and applications of Aloe vera leaf gel, Molecules 13 (8) (2008) 1599-1616. 
[33] S. Choi, M.-H. Chung, A review on the relationship between aloe vera components and their biologic effects, Semin. Integr. Med. 1 (1) (2003) 53-62.

[34] K.H. Kim, Y.J. Hwang, S.C. Bai, Resistance to Vibrio alginolyticus in juvenile rockfish (Sebastes schlegeli) fed diets containing different doses of aloe, Aquaculture $180(1-2)(1999)$ 13-21.

[35] F.S. Zanuzzo, J.D. Biller-Takahashi, E.C. Urbinati, Effect of Aloe vera extract on the improvement of the respiratory activity of leukocytes of matrinxa during the transport stress, Rev. Bras. Zootecn 41 (10) (2012) 2299-2302.

[36] F.S. Zanuzzo, E.C. Urbinati, M.L. Rise, J.R. Hall, G.W. Nash, A.K. Gamperl, Aeromonas salmonicida induced immune gene expression in Aloe vera fed steelhead trout, Oncorhynchus mykiss (Walbaum), Aquaculture 435 (0) (2015) $1-9$.

[37] E. Abdy, M. Alishahi, M.R. Tabandeh, M. Ghorbanpoor, H. Jafari, Comparative effect of Freund's adjuvant and Aloe vera L. gel on the expression of TNF- $\alpha$ and IL-1 $\beta$ in vaccinated Cyprinus carpio L. with Aeromonas hydrophila C. bacterin, Aquac. Res. 17 (8) (2015) 2543-2552.

[38] F.S. Zanuzzo, S.F. Zaiden, J.A. Senhorini, C.M. Marzocchi-Machado, E.C. Urbinati, Aloe vera bathing improved physical and humoral protection in breeding stock after induced spawning in matrinxã (Brycon amazonicus), Fish. Shellfish Immunol. 45 (1) (2015) 132-140.

[39] N.N. Gabriel, J. Qiang, J. He, X.Y. Ma, M.D. Kpundeh, P. Xu, Dietary Aloe vera supplementation on growth performance, some haemato-biochemical parameters and disease resistance against Streptococcus iniae in tilapia (GIFT), Fish. Shellfish Immunol. 44 (2) (2015) 504-514.

[40] E. Abdy, M. Alishahi, M. Tollabi, M. Ghorbanpour, T. Mohammadian, Comparative effects of Aloe vera gel and Freund's adjuvant in vaccination of common carp (Cyprinus carpio L.) against Aeromonas hydrophila, Aquacult. Int. (2016) $1-16$.

[41] N.N. Gabriel, J. Qiang, X.Y. Ma, J. He, P. Xu, K. Liu, Dietary Aloe vera improves plasma lipid profile, antioxidant, and hepatoprotective enzyme activities in GIFT-tilapia (Oreochromis niloticus) after Streptococcus iniae challenge, Fish. Physiol. Biochem. 41 (5) (2015) 1321-1332.

[42] P. Chithra, G.B. Sajithlal, G. Chandrakasan, Influence of Aloe vera on collagen characteristics in healing dermal wounds in rats, Mol. Cell Biochem. 181 (1-2) (1998) 71-76.

[43] A.O.A.C, Official Methods of Analysis, 13a., Ed., Association of Official Analytical Chemists, Washington, 1984.

[44] V.R. Reque, J.R.E. de Moraes, M.A.D. Belo, F.R. de Moraes, Inflammation induced by inactivated Aeromonas hydrophila in Nile tilapia fed diets supplemented with Saccharomyces cerevisiae, Aquaculture 300 (1-4) (2010) 37-42.

[45] P.K. Sahoo, J. Kumari, B.K. Mishra, Non-specific immune responses in juveniles of Indian major carps, J. Appl. Ichthyol. 21 (2) (2005) 151-155.

[46] N.E. Demers, C.J. Bayne, The immediate effects of stress on hormones and plasma lysozyme in rainbow trout, Dev. Comp. Immunol. 21 (4) (1997) 363-373.

[47] S.K. Dugenci, N. Arda, A. Candan, Some medicinal plants as immunostimulant for fish, J. Ethnopharmacol. 88 (1) (2003) 99-106.

[48] C. Bulfon, D. Volpatti, M. Galeotti, Current research on the use of plant-derived products in farmed fish, Aquacult. Res. 46 (3) (2013) 513-551.

[49] S. Maqsood, P. Singh, M.H. Samoon, K. Munir, Emerging role of immunostimulants in combating the disease outbreak in aquaculture, Int. Aquat. Res. 3 (2011) 147-163.

[50] S.E. Wendelaar Bonga, the stress response in fish, Physiol. Rev. 77 (3) (1997) $591-625$.

[51] W.B. Wang, A.H. Li, T.Z. Cai, J.G. Wang, Effects of intraperitoneal injection of cortisol on nonspecific immune functions of Ctenopharyngodon idella, J. Fish. Biol. 67 (3) (2005) 779-793.

[52] G. Nardocci, C. Navarro, P.P. Cortes, M. Imarai, M. Montoya, B. Valenzuela, P. Jara, C. Acuna-Castillo, R. Fernandez, Neuroendocrine mechanisms for immune system regulation during stress in fish, Fish. Shellfish Immunol. 40 (2) (2014) 531-538.

[53] F.S. Zanuzzo, E.C. Urbinati, G.W. Nash, A.K. Gamperl, Steelhead trout Oncorhynchus mykiss metabolic rate is affected by dietary Aloe vera inclusion but not by mounting an immune response against formalin-killed Aeromonas salmonicida, J. Fish. Biol. 87 (1) (2015) 43-53.

[54] B.M. Babior, R.S. Kipnes, J.T. Curnutte, Biological defense mechanisms production by leukocytes of superoxide a potential bactericidal agent, J. Clin. Invest. 52 (3) (1973) 741-744.

[55] V. Selvaraj, K. Sampath, V. Sekar, Adjuvant and immunostimulatory effects of $\beta$-glucan administration in combination with lipopolysaccharide enhances survival and some immune parameters in carp challenged with Aeromonas hydrophila, Vet. Immunol. Immunop 114 (1-2) (2006) 15-24.

[56] X.F. Zhang, H.M. Wang, Y.L. Song, L.H. Nie, L.F. Wang, B. Liu, P.P. Shen, Y. Liu, Isolation, structure elucidation, antioxidative and immunomodulatory properties of two novel dihydrocoumarins from Aloe vera, Bioorg. Med. Chem. Lett. 16 (4) (2006) 949-953.

[57] D. Christybapita, M. Divyagnaneswari, R.D. Michael, Oral administration of Eclipta alba leaf aqueous extract enhances the non-specific immune responses and disease resistance of Oreochromis mossambicus, Fish. Shellfish Immunol. 23 (4) (2007) 840-852.

[58] L. Ardo, G. Yin, P. Xu, L. Varadi, G. Szigeti, Z. Jeney, G. Jeney, Chinese herbs (Astragalus membranaceus and Lonicera japonica) and boron enhance the nonspecific immune response of Nile tilapia (Oreochromis niloticus) and resistance against Aeromonas hydrophila, Aquaculture 275 (1-4) (2008) 26-33.
[59] S. Saurabh, P.K. Sahoo, Lysozyme: an important defence molecule of fish innate immune system. Aquacult. Res. 39 (3) (2008) 223-239.

[60] A. Siwicki, M. Studnicka, The phagocytic ability of neutrophils and serum lysozyme activity in experimentally infected carp, Cyprinus carpio L, J. Fish. Biol. 31 (1987) 57-60.

[61] K. Moyner, K.H. Roed, S. Sevatdal, M. Heum, Changes in nonspecific immune parameters in Atlantic Salmon, Salmo salar L, induced by Aeromonas salmonicida infection, Fish. Shellfish Immunol. 3 (4) (1993) 253-265.

[62] V.K. Verma, K.V. Rani, N. Sehgal, O. Prakash, Immunostimulatory effect of artificial feed supplemented with indigenous plants on Clarias gariepinus against Aeromonas hydrophila, Fish. Shellfish Immunol. 35 (6) (2013) 1924-1931.

[63] H. Boshra, J. Li, J.O. Sunyer, Recent advances on the complement system of teleost fish, Fish. Shelliish Immunol. 20 (2) (2006) 239-262.

[64] S.C. Zhang, P.F. Cui, Complement system in zebrafish, Dev. Comp. Immunol. 46 (1) (2014) 3-10.

[65] L. Tort, E. Gomez, D. Montero, J.O. Sunyer, Serum haemolytic and agglutinating activity as indicators of fish immunocompetence: their suitability in stress and dietary studies, Aquacult. Int. 4 (1) (1996) 31-41.

[66] G. Jeney, D.P. Anderson, Glucan injection or bath exposure given alone or in combination with a bacterin enhance the nonspecific defense mechanisms in Rainbow trout (Oncorhynchus mykiss), Aquaculture 116 (4) (1993) 315-329.

[67] R.E. Engstad, B. Robertsen, E. Frivold, Yeast glucan induces increase in lysozyme and complement-mediated haemolytic activity in Atlantic salmon blood, Fish. Shellfish Immunol. 2 (4) (1992) 287-297.

[68] H. Matsuyama, R.E.P. Mangindaan, T. Yano, Protective effect of schizophyllan and scleroglucan against Streptococcus sp Infection in Yellowtail (Seriola quinqueradiata), Aquaculture 101 (3-4) (1992) 197-203.

[69] K.H. Park, S.H. Choi, The effect of mistletoe, Viscum album coloratum, extract on innate immune response of Nile tilapia (Oreochromis niloticus), Fish. Shellfish Immunol. 32 (6) (2012) 1016-1021.

[70] G. Yogeshwari, C. Jagruthi, S.M. Anbazahan, L.S.S. Mari, J. Selvanathan, J. Arockiaraj, N.B. Dhayanithi, T.T. Ajithkumar, C. Balasundaram, H. Ramasamy, Herbal supplementation diet on immune response in Labeo rohita against Aphanomyces invadans, Aquaculture 437 (0) (2015) 351-359.

[71] C.P. Alexander, C.J.W. Kirubakaran, R.D. Michael, Water soluble fraction of Tinospora cordifolia leaves enhanced the non-specific immune mechanisms and disease resistance in Oreochromis mossambicus, Fish. Shellfish Immunol 29 (5) (2010) 765-772.

[72] C.J.W. Kirubakaran, C.P. Alexander, R.D. Michael, Enhancement of non-specific immune responses and disease resistance on oral administration of Nyctanthes arbortristis seed extract in Oreochromis mossambicus (Peters), Aquacult. Res. 41 (11) (2010) 1630-1639.

[73] R. Harikrishnan, C. Balasundaram, M.C. Kim, J.S. Kim, Y.J. Han, M.S. Heo, Innate immune response and disease resistance in Carassius auratus by triherbal solvent extracts, Fish. Shellfish Immunol. 27 (3) (2009) 508-515.

[74] R. Harikrishnan, J. Heo, C. Balasundaram, M.C. Kim, J.S. Kim, Y.J. Han, M.S. Heo, Effect of Punica granatum solvent extracts on immune system and disease resistance in Paralichthys olivaceus against lymphocystis disease virus (LDV), Fish. Shellfish Immunol. 29 (4) (2010) 668-673.

[75] D.O. Adams, T.A. Hamilton, The cell biology of macrophage activation, Annu. Rev. Immunol. 2 (1984) 283-318.

[76] J. Rotllant, D. Parra, R. Peters, H. Boshra, J.O. Sunyer, Generation, purification and functional characterization of three $\mathrm{C} 3$ a anaphylatoxins in rainbow trout: role in leukocyte chemotaxis and respiratory burst, Dev. Comp. Immunol. 28 (7-8) (2004) 815-828.

[77] M. Nakao, M. Tsujikura, S. Ichiki, T.K. Vo, T. Somamoto, The complement system in teleost fish: progress of post-homolog-hunting researches, Dev. Comp. Immunol. 35 (12) (2011) 1296-1308.

[78] N. Pugh, S.A. Ross, M.A. ElSohly, D.S. Pasco, Characterization of aloeride, a new high-molecular-weight polysaccharide from Aloe vera with potent immunostimulatory activity, J. Agric. Food Chem. 49 (2) (2001) 1030-1034.

[79] L. Ramamoorthy, I.R. Tizard, Induction of apoptosis in a macrophage cell line RAW 264.7 by acemannan, a beta-(1,4)-acetylated mannan, Mol. Pharmacol. 53 (3) (1998) 415-421.

[80] K. Takeda, T. Kaisho, S. Akira, Toll-like receptors, Annu. Rev. Immunol. 21 (2003) 335-376.

[81] S. Akira, S. Uematsu, O. Takeuchi, Pathogen recognition and innate immunity, Cell 124 (4) (2006) 783-801.

[82] H. Heine, E. Lien, Toll-like receptors and their function in innate and adaptive immunity, Int. Arch. Allergy. Imm 130 (3) (2003) 180-192.

[83] B.M. Shao, W. Xu, H. Dai, P.F. Tu, Z.J. Li, X.M. Gao, A study on the immune receptors for polysaccharides from the roots of Astragalus membranaceus, a Chinese medicinal herb, Biochem. Biophys. Res. Commun. 320 (4) (2004) 1103-1111.

[84] S.B. Han, Y.D. Yoon, H.J. Ahn, H.S. Lee, C.W. Lee, W.K. Yoon, S.K. Park, H.M. Kim, Toll-like receptor-mediated activation of B cells and macrophages by polysaccharide isolated from cell culture of Acanthopanax senticosus, Int. Immunopharmacol. 3 (9) (2003) 1301-1312.

[85] Y.D. Yoon, S.B. Han, J.S. Kang, C.W. Lee, S.K. Park, H.S. Lee, J.S. Kang, H.M. Kim, Toll-like receptor 4-dependent activation of macrophages by polysaccharide isolated from the radix of Platycodon grandiflorum, Int. Immunopharmacol. 3 (13-14) (2003) 1873-1882.

[86] G. Hajishengallis, J.D. Lambris, Crosstalk pathways between Toll-like receptors and the complement system, Trends Immunol. 31 (4) (2010) 154-163. 
[87] J.C. Kagan, R. Medzhitov, Phosphoinositide-mediated adaptor recruitment controls toll-like receptor signaling, Cell 125 (5) (2006) 943-955.

[88] X.H. Zhang, Y. Kimura, C.Y. Fang, L. Zhou, G. Sfyroera, J.D. Lambris, R.A. Wetsel, T. Miwa, W.C. Song, Regulation of Toll-like receptor-mediated inflammatory response by complement in vivo, Blood 110 (1) (2007) 228-236.

[89] D.J. Kaczorowski, A. Afrazi, M.J. Scott, J.H. Kwak, R. Gill, R.D. Edmonds, Y.J. Liu, J. Fan, T.R. Billiar, Pivotal Advance: the pattern recognition receptor ligands lipopolysaccharide and polyinosine-polycytidylic acid stimulate factor B synthesis by the macrophage through distinct but overlapping mechanisms, J. Leukoc. Biol. 88 (4) (2010) 609-618.

[90] Z.X. Zhou, B.C. Zhang, L. Sun, Poly(I: C) Induces antiviral immune responses in
Japanese flounder (Paralichthys olivaceus) that require TLR3 and MDA5 and is negatively regulated by Myd88, Plos One 9 (11) (2014).

[91] Z.-X. Zhou, L. Sun, Immune effects of R848: evidences that suggest an essential role of TLR7/8-induced, Myd88- and NF-KB-dependent signaling in the antiviral immunity of Japanese flounder (Paralichthys olivaceus), Dev. Comp. Immunol. 49 (1) (2015) 113-120.

[92] A. Falco, J.J. Miest, N. Pionnier, D. Pietretti, M. Forlenza, G.F. Wiegertjes, D. Hoole, $\beta$-Glucan supplemented diets increase poly(I: C)-induced gene expression of $\mathrm{Mx}$, possibly via Tlr3-mediated recognition mechanism in common carp (Cyprirtus carpio), Fish. Shellfish Immunol. 36 (2) (2014) 494-502. 